\title{
A GINÁSTICA RÍTMICA E OS PRINCÍPIOS METODOLÓGICOS
}

\author{
Cleiton Teixeira da Silva ${ }^{1}$ \\ Wilza Mary Saraiva Mourão ${ }^{2}$
}

RESUMO: O presente estudo apresenta algumas contribuições acerca das metodologias e técnicas advindas da Ginástica Rítimica, nas aulas de Educação Física Escolar no processo de ensino-aprendizagem. O objetivo geral desta pesquisa é identificar a importância de metodologias e técnicas que reflitam sobre as aulas de GR nas aulas de educação física, identificando a influência do lúdico nesse processo. A partir das discussões levantadas, observa-se que a utilização do lúdico no ensino-aprendizado da Ginástica Rítmica é um elemento motivador onde o aluno pode criar o hábito da prática da modalidade posteriormente. Muitas bibliografias de ensino da GR tem seu foco no ensino da técnica como principal (tecnicista), onde é estimulado e ensinado a repetição dos fundamentos e técnicas desvinculados do contexto das práticas propriamente ditas, como do contexto social. A metodologia empregada é a exploratória/bibliográfica e expositiva/qualitativa em que utilizamos algumas das principais referências bibliográficas dessa temática. São inúmeras possibilidades metodológicas quando se trabalha com o lúdico como princípio pedagógico/educativo, por ampliar o envolvimento dos alunos de maneira prazerosa nas aulas. Outro aspecto é a compreensão da lógica interna e seus aspectos identificadores da Ginástica Rítimica, bem como algumas técnicas específicas que possibilitam uma melhor aplicabilidade, com isso a possibilidade dos alunos se interessarem por esse esporte depois dessa fase inicial de aprendizagem.

Palavras-chave: Ginástica Rítimica. Educação Física. Escola. Metodologias. Técnica.

ABSTRACT: This study presents some contributions about methodologies and techniques arising from Rhythmic Gymnastics, in School Physical Education classes in the teaching-learning process. The general objective of this research is to identify the importance of methodologies and techniques that reflect on the GR classes in physical education classes, identifying the influence of play in this process. From the discussions raised, it is observed that the use of play in the teaching-learning of Rhythmic Gymnastics is a motivating element where the student can create the habit of practicing the modality later on. Many GR teaching bibliographies have their focus on teaching technique as the main (technicist), where repetition of fundamentals and techniques disconnected from the context of actual practices, such as the social context, is encouraged and taught. The methodology used is exploratory/bibliographic and expository/qualitative, in which we use some of the main bibliographical references on this topic. There are countless

\footnotetext{
${ }^{1}$ Acadêmico do 8 o período do Curso de Educação Física, da UNIBRÁS - Faculdade de Rio Verde. Email: Cleitonteixeirar998@gmail.com.

2 Professora do Curso de Educação Física, da UNIBRÁS - Faculdade de Rio Verde e Orientador da respectiva pesquisa.E-mail: Wilza.mourao@gmail.com.
} 
methodological possibilities when working with playfulness as a pedagogical/educational principle, as it expands the involvement of students in a pleasurable way in classes. Another aspect is the understanding of the internal logic and its identifying aspects of Rhythmic Gymnastics, as well as some specific techniques that allow for a better applicability, thus allowing students to become interested in this sport after this initial stage of learning.

Keywords: Rhythmic Gymnastics. PE. School. Methodologies. Technique.

\section{INTRODUÇÃO}

A Ginástica Rítmica segundo Lafranchi (200I) é considerada um tipo de esporte ginástico, sendo ela uma modalidade exclusivamente feminina, e muito graciosa pelos seus movimentos plásticos e expressivos (LAFRANCHI, 200I).

Assim, a GR como esporte que exige extrema flexibilidade muscular e articular e coordenação com os aparelhos obrigatórios bola, fita, arco, corda e maças (GAIO, 2008, p. 17). Uma composição coreográfica de GR engloba dificuldades obrigatórias da ginástica rítmica, acrobacia, dança, arte coreográfica, criatividade e manejo dos aparelhos. A série pode ser a mãos livres ou então com um dos cinco aparelhos (LAFRANCHI, 200I; SANTOS, et al, 2010).

O respectivo estudo, possui por intenção maior, oferecer importantes reflexões acerca do Ensino da Ginástica Rítmica, visto ser este um relevante conteúdo da Educação Física escolar e expressivo componente da cultura corporal, bem como a abordagem desta temática acredita ser tratada, porque, contraditoriamente, sua concepção e manifestação têm sido pouco utilizada nos dias atuais, mesmo que seja muito procurada, sendo ela uma das mais diversificadas, com visível proliferação de modalidades, visões e métodos de ensino, variadas inserções, origens, finalidades $e$ possibilidades de acesso e experimentação.

Frente a essas considerações esse trabalho possui como temática, "Estudo Exploratório das Aulas de Educação Física: A Ginástica Rítmica e os Princípios Metodológicos”, explorando seu contexto educacional, no universo escolar.

A Ginástica Rítmica passa a ser praticada desde o final da Primeira Guerra Mundial, porém não possuía regras especificas nem um nome determinado. Diversas escolas inovavam os exercícios tradicionais da Ginástica Artística, misturando-os com 
música, onde em meados de 1946, na Rússia, surge o termo rítmica, devido à utilização da música e da dança durante a execução de movimentos.

Hoje em dia o a Ginástica Rítimica vem cada vez mais aumentando seu número de adeptos, praticantes e simpatizantes, por se tratar de movimentos criativos, dinâmicos, variadoss e empolgante.

Contudo, o problema que norteia esse estudo buscou responder ao seguinte questionamento: "Como o professor de Educação Física pode incluir a Ginástica Rítimica, em suas aulas escolares, propondo atividades dinâmicas e lúdicas, e assim, contribuir para o ensino-aprendizado dos alunos?”

Uma das hipóteses culimina em refletir sobre as relações metodológicas e ações pedagógicas nas aulas de Educação Física Escolar, devendo o professor buscar a implantação de uma hegemonia nos pensamentos científicos e teóricos desta área, contemplando-se assim num ensino reflexivo, que favorece ricamente no processo de aprendizagem desta modalidade, fugindo do tradicionalismo, capacitando seus profissionais e inovando, sempre levando em consideração que este é um processo que se exige esforço, dedicação, força de vontade e formação continuada.

$\mathrm{O}$ objetivo geral desta pesquisa se entrelaça frente a: Identificar a importância de metodologias e técnicas que reflitam sobre as aulas de handebol nas aulas de educação física, identificando a influência do lúdico nesse processo. Os objetivos que norteiam esse estudo são: - Apontar a origem da Ginástica Rítmica, em especial, na escola; Compreender os aspéctos históricos da Educação Física; - Refletir quais são os aspectos Metodológicos e a importância do lúdico no processo de Ensino-aprendizagem; - Fomentar algumas das expectativas sobre a aprendizagem da Ginástica Rítimica, no contexto escolar; - Rever quais são algumas das propostas para instigar o gosto pela prática da Ginástica Rítimica, na escola, tendo amparo da BNCC.

Contudo, assim como toda prática de movimentos, a Ginástica Rítmica possui características dinâmicas/diversificadas que permitem desenvolver nos praticantes a socialização e que também instiga nos seus, traços de personalidade, criatividade, organização, espírito de equipe, coleguismo, aceitabilidade, responsabilidade, disciplina, resistência física, coragem, afeto e solidariedade.

O trabalho busca estudar a Ginástica Rítimica, enquanto prática de lazer e 
transformá-la em um tipo de prática corporal acessível a todos, por meio, de conteúdos lúdicos que façam os praticantes sentirem prazer em praticar essa modalidade e ainda consigam desenvolver os fundamentos com eficiência, possibilitando assim aumentar o número de praticante dessa cultura corporal.

A pesquisa procurou observar a perspectiva do lúdico no ensino-aprendizado da Ginástica Rítmica escolar, juntamente com as técnicas e metodologias como métodos para atingir um resultado benéfico e com aproveitando. A pesquisa foi realizada através de pesquisa bibliográfica, de cunho qualitativo, sobre as atividades lúdicas para o ensinoaprendizado da Ginástica Rítimica, onde será verificado se o método vai despertar no aluno, o interesse em praticar a modalidade. Para alcançar o objetivo geral, realizou-se um levantamento bibliográfico, onde observou-se o histórico da Ginástica Rítimica e seus fundamentos.

Para o desenvolvimento do respectivo estudo, elegeu-se uma pesquisa bibliográfica, de cunho e qualitativo, com a intenção de buscar informações fundamentadas em livros, artigos, dissertações, trabalhos acadêmicos diversos em formatos de teses e monografias, no que tange a finalidade de se desenvolver uma revisão da literatura sobre a temática em pauta, com o objetivo maior, culminou em realizar uma avaliação crítica dos estudos e fundamentação científica, que culminaram para toda construção desse trabalho.

Esse trabalho contou com o amparo de uma pesquisa bibliográfica que conforme Marconi e Lakatos (2017) abrangem publicações em relação ao tema de estudo, conando com uma revisão da literatura utilizando as bases de dados das plataformas, LILACS, PubMed, Google Acadêmico, Scielo, Bireme, além de livros.

Pode-se afirmar quanto a esse trabalho, que o mesmo abordará uma abordagem qualitativa, já que esse tipo de procedimento busca analisar os dados da realidade do contexto estudado que podem ou não podem ser quantificados e quanto aos objetivos tratase de uma pesquisa exploratória (GIL, 2010).

Foram selecionados artigos de 2003 a 2020, com temas relacionados à a intervenção da Fisioterapia frente a prevenção de lesões em atletas de voleiboli. Sendo os resultados apresentados de forma descritiva.

A pesquisa foi realizada nos idiomas de Língua Portuguesa e de Língua Inglesa, utilizando-se assim das seguintes palavras-chave: Ginástica Rítimica; Contexto Escolar; 
Fundamentos; Importância e Lúdico.

Portanto, o procedimento metodológico desse trabalho está disposto em formato de Revisão de Literatura, sobe um diálogo exploratório-bibliográfico, de cunho qualitativo e de natureza básica, tendo por estrutura teórica, obras de renomados autores que abordam com grande conhecimento e coerência, a temática supracitada nessa pesquisa.

\section{REVISÃO DA LITERATURA}

\section{I Aspectos Históricos Da Educação Física}

Faz-se necessário realizar um apanhado da história da Educação Física, pelo qual passará a dialogar com autores que aplicaram suas metodologias inseridas em tendências pedagógicas iniciais até os dias de hoje, será abordado algumas das principais tendências pedagógicas atuais da Educação Física escolar, com seus conceitos, relevâncias e implicações.

Segundo Rodrigues (1998), a origem histórica da Educação Física está relacionada à institucionalização da ginástica e tem como locus a Europa do século XIX. No Brasil, a Educação Física esteve sob influência de três instituições, a médica, a militar e a esportiva, sendo baseadas nos diversos paradigmas como: higiesnismo, eugenismo e da aptidão física respectivamente, onde a identidade pedagógica escolar era calcada nas normas e nos valores dessas instituições.

Esta autora ressalta que Pagni vê a ginástica como instrumento necessário na educação das crianças e dos jovens, bem como deveria ser ministrada às novas gerações. Esse mesmo autor relata que o educador Fernando de Azevedo (1894-1974) foi o precursor das primeiras propostas pedagógicas sobre a Educação Física e o esporte, onde segundo o próprio AZEVEDO: “a educação física é a atividade esportiva representam hábitos salutares e modernos, proporcionando àqueles que as praticam benefícios higiênicos e morais, fatores básicos para a regeneração sócio-cultural”.

De acordo com Ghiraldelli Jr. (1991), os professores de Educação Física que atuavam nas escolas eram instrutores formados pelas instituições militares. Vale ressaltar que a Educação Física nessa época era confundida com a Ginástica, termo esse que aparece, quando se trata da origem histórica da mesma.

Seguindo a mesma ideia do autor acima, Bregolato (2006) relata que devido às 
guerras e revoluções ocorridas no período do século XIX, a formação física e moral da ginástica foi voltada principalmente para fim nacionalista de lutar pela pátria; e isso fez com que gerasse a maior corrente do Movimento Ginástico Europeu, a Tendência Militarista, que concebia formar indivíduos saudáveis, fortes e de caráter para servir a nação.

Conforme a mesma autora, citada anteriormente, os exercícios ginásticos promovem a saúde, a força e a determinação, que eram quesitos de um guerreiro para bem servir a nação.

Após a tendência Militarista ter vigorado na época, houve outra corrente, a Tendência Naturalista ou Método Natural, que não se justificava nos anseios da nação, mas na pessoa em si mesma, portanto, os benefícios que a ginástica proporcionava eram revertidos para o praticante (BREGOLATO, 2006).

No século XX, partindo da reflexão de Marcassa (2000), houve uma concentração de riquezas e de desenvolvimento urbano, o governo preocupou-se em modernizar, moralizar e higienizar a nação brasileira, e a autora ressalta que "a escola surge como um espaço de desenvolvimento moral e higiênico da população urbana” (p. 84).

A Educação Física no Brasil nesse momento torna-se uma área de interesse de muitos pedagogos, que passam a defender e estimular a prática como forma de "educar o corpo", mas ainda muito presente as influências da fisiologia do exercício, do esporte de rendimento e com ele todos os valores e ideais olímpicos notáveis na década de 7o.

Já nos anos 8o, segundo Rodrigues (1998), com o fim do regime autoritário, começa a busca de um outro paradigma, além da aptidão física, este agora com teorias gestadas e baseadas em princípios diversos, resultando em um avanço no número de pesquisa sobre a Educação Física no meio acadêmico, "Surge então a Psicomotricidade e suas variantes, como a psicocinética de Le Bouch (1987), as quais vêm contestar os métodos fisiológicos - adestradores de ensino infantil” (p. ı)).

Ainda segundo Rodrigues (1998, p. II):

Atualmente, a escola brasileira convive com várias correntes de Educação Física simultaneamente. Isso ocorre porque ao surgir uma nova concepção de educação física, as anteriores não morrem, elas continuam vivas e disputando espaço às vezes de forma conflituosa, às vezes de forma conciliadora. (RODRIGUES, 1998, p. II)

Logo depois da Psicomotricidade surge a abordagem Desenvolvimentista, a qual 
seus autores defendem a ideia de que o movimento é o eixo principal; pois auxilia nas habilidades motoras, ou seja, aprendizagem motora.

$\mathrm{Na}$ abordagem Crítico - Superadora, segundo Darido (2005), citando Soares, ela é baseada no marxismo, fazendo um resgate histórico para uma maior compreensão do aluno na questão de esclarecer as mudanças que houve ao longo do tempo, com o objetivo de ler, interpretar e transformar a realidade com características de defesa da classe trabalhadora.

Kunz citado por Darido e Neto (2005), relata sobre o surgimento da tendência Crítico - Emancipatória como a mesma sendo um desdobramento da abordagem Crítico Superadora, valorizando a compreensão crítica do mundo e também tendo esse mesmo tipo de compreensão da sociedade e de suas relações; assumindo a utopia existente no processo de ensino e aprendizagem, propondo elevar os graus de liberdade e criticidade nos alunos sem mencionar aspectos da realidade (social) nem de classe social.

Retornando o paradigma da aptidão física surge a abordagem saúde renovada relacionada à Saúde com objetivos de informar, mudar atitudes e promover a prática sistemática de exercícios.

Neste sentido Darido (2005), afirma que os PCNs, (Parâmetros Curriculares Nacionais), indicam uma possibilidade de aproximação entre as tendências propostas no componente curricular Educação Física. Isso vem a propor uma construção crítica da cidadania, partindo do entendimento que a Educação Física na escola passe a promover a inclusão e integração dos alunos à Cultura Corporal de Movimento, por meio de vivências que problematizem criticamente os conteúdos que são: jogos, esportes, danças, ginásticas, lutas e conhecimento sobre o corpo.

\subsection{Aspectos Metodológicos: A Importância Do Lúdico No Processo Ensino- Aprendizagem}

Contudo a Educação Física como prática pedagógica, remete a pensar que ela possui um papel importante na construção do conhecimento, pois é uma área onde o processo de ensino e aprendizagem ocorre corporalmente, sendo possível assim potencializar transformações sociais (DARIDO, 2005).

É possível assim, uma ressignificação sobre a inserção de novos métodos de ensino-aprendizagem, ao repensar como são aplicadas nas atividades do handebol durante as aulas de Educação Física Escolar, podendo ser caracterizadas como práticas corporais e 
como os educandos se adaptarão, tomando gosto por elas.

O professor quando for elaborar suas aulas, selecionar e/ou criar atividades mais significativas para seus alunos, aquelas que irão proporcionar uma experiência próxima da realidade das práticas corporais da Ginástica Rítimica. Em seguida o professor deve criar condições para que estas atividades sejam realizadas. Destaca-se a importância de os alunos trabalharem seja individualmente ou em grupos, interagindo uns com outros, e esse trabalho facilitará o desenvolvimento individual e consequentemente o coletivo ( LISBOe TEIXEIRA, 2012).

Afirma MOYLES (2002, p. Ior) que:

\begin{abstract}
Mas se o papel do professor é o de iniciador e medidor da aprendizagem, e o de provedor da estrutura dentro das quais as crianças podem explorar, brincar, planejar e assumir a responsabilidade por sua aprendizage m, isso faz as coisas ficarem muito diferentes. Mais importante, esta abordagem certamente libera os professores para passar mais tempo com as crianças. O professor se torna um organizador efetivo da situação de aprendizagem, na qual ele reconhece, afirma e apóia as oportunidades para a criança aprender à sua própria maneira, em seu próprio nível e a partir de suas experiências passadas (conhecimentos prévios). (MOYLES, 2002, p. IOI)
\end{abstract}

Cabe ao professor construir metodologias e condições para desenvolver e facilitar à aprendizagem. A identidade do grupo tem como resultado a relação de atividades mais amplas e profundas, como do tipo de liderança, respeito aos colegas, perspectivas de evolução, compreensão e ajuda mútua, aceitação. São estas algumas das qualidades que podem ser trabalhadas pelos professores (LISBOA e TEIXEIRA, 2012).

Os professores têm como possibilidade trabalhar com seus alunos a ludicidade nas aulas como um caminho para a transposição/transferência desses aspectos à vida cotidiana posterior a essa formação e principalmente atividades que possam sempre estimular as capacidades dos alunos sob todos os aspectos, pois:

Os professores precisam trabalhar dentro das capacidades das crianças, mas, em todas as áreas, e especialmente na educação física, devem estar preparados para proporcionar o desenvolvimento das capacidades singulares, a fim de que os alunos obtenham os sentimentos de bem estar físico e mental desejados. (MOYLES, 2002, p. 43).

Vale ressaltar que as atividades corporais de movimentos são muito importantes, pois através da sua prática e juntamente com jogos lúdicos, os alunos podem demonstrar interesse e motivação para continuarem a praticar a Ginástica Rítimica, além de melhorar aspectos da qualidade de vida, evitando o sedentarismo. Com a prática corporal, os alunos 
podem reconhecer e controlar melhor seu corpo, seus limites e as possibilidades que pode exercer, além da possibilidade de se trabalhar a autoestima e resultados na sua criatividade, integração social e na melhoria de vida do seu cotidiano (RINALDI e PAOLIELLO, 2008).

Sabe-se também que a prática da Ginástica Rítimica não é apenas a prática da Ginástica em si, mas um processo que fomenta o desenvolvimento intelectual, social, emocional, afetivo, cognitivo e físico. Através das atividades lúdicas pode-se dizer que os alunos assimilam conceitos relacionados à prática de movimentos, como: coletivo $\mathrm{x}$ individualismo, criatividade, resolução de problemas, disciplina, coragem, dedicação, persistência, responsabilidade, crítica e autocrítica, onde a forma prazerosa traz consigo o distencionamento das relações de ensino-aprendizagem, superando assim as relações tradicionais educativas (RINALDI e PAOLIELLO, 2008).

O lúdico aliado ao ensino da técnica de qualquer modalidade de movimento pode contribuir na aprendizagem dos alunos, desta forma faz-se necessário que os professores de Educação Física tenham em mente que a prática diversificada na escola é diferente da utilizada no alto rendimento de competições fora da escola, pois são vários os fatores que diferenciam uma da outra, como a competividade, o caráter informal/formal, dentre outrosetc. Para Moyles (2002), a escola tem por finalidade maior oferecer aos seus alunos práticas de atividades com maior ludicidade, sendo assim como um caminho que possa sempre estimular as capacidades dos alunos, sob todos os aspectos corporais.

Portanto, percebe-se que há uma considerável importância nas atividades advindas da Ginástica Rítimica, onde constituem-se assim uma significativa relevância na vida dos alunos, pois permite a eles, aprenderem parcialmente algumas técnicas referentes aos primeiros movimentos da Ginástica Rítimica, ministrados durante as aulas de educação física, convivendo também assim com outras culturas, aprendendo a necessidade de se praticar algum tipo de movimento corporal sistematizado, onde já nos primeiros anos escolares, o aluno toma gosto ou não, pelas atividades que a Educação Física propõe, tarefa esta também da escola, de buscar métodos que incentivem os seus, pois ali no âmbito escolar, o aluno ao interagir-se com outros colegas desenvolvendo suas habilidades, saberes e aprendizados acerca de tudo que a Ginástica Rítmica pode proporcionar (RINALDI e 
SOUZA, 2003).

Assim podemos levar sempre em consideração que as práticas da Ginástica Rítimica necessitam ser inseridas de maneira lúdica, pedagógica e prazerosa, sempre se levando em consideração o conhecimento empírico que cada aluno traz consigo, para que então desta maneira os mesmos peguem gosto por esta prática de movimentos rítmicos.

O professor deve estimular o processo de ensino e função da aprendizagem dos alunos, utilizando um conjunto de ações, passos, condições externas e procedimentos a que se chama de métodos de Ensino. $O$ método de ensino expressa a relação conteúdo-método, tendo como base um conteúdo determinado que vai em busca de um objeto, problema, fenômeno (LIBÂNEO, I994, p.3)

Os conteúdos vão sendo ministrados conforme a necessidade dos aprendizes e da comunidade, por isto o docente, poderá buscar seus objetivos e colocá-los em prática, na constante busca por bons resultados no processo de ensino-aprendizado do contexto escolar, caracterizados através das relações humanas presentes nos aspectos: afetivos, motores cognitivos e suas relações sociais, globais e culturais (RINALDI e SOUZA, 2003).

As ações adquiridas no intercâmbio de informações entre professor e aluno, informações estas vindas através dos órgãos de sentidos, bem como a experiência e conhecimentos que cada um traz em sua bagagem na modalidade praticada. Oiveira et al., (2012, p.24) considera que:

O educador na sua prática, é um veiculador de valores. Desta maneira, o educador ao desenvolver seu trabalho, pode e muito exercer sua função, podendo então influenciar e moldar o caráter do aluno e deixar marcas nos mesmos em formação, ele é responsável por muitos descobrimentos e experiências que podem ter aspectos positivos ou não, por isso o professor deve ir além do trabalho físico e motor, abordando aspectos sociais, culturais e psicológicos. (OLIVEIRA, et al., 2012, p.24).

Torna-se de grande importância explicitar aos alunos as tendências lúdicas e pedagógicas que existem no campo da Educação Física para prática da Ginástica Rítimica e assim sendo, buscar fazer um direcionamento através da introdução do ensino das técnicas e táticas do esporte, para a formação de valores globais e sociais na vida destes.

Por isso, o professor que leva em consideração primeiramente o ensino/aprendizagem, conseguindo fazê-lo de maneira harmônica, primando-se pela ação, onde amplia-se experiências ocorridas pelo processo de reconstrução dos conhecimentos, o 
que requer o domínio sobre ele, aumentando então assim os conhecimentos e a interação entre professor-aluno, transformando as atividades da Ginástica Rítmica, como excelência exclusiva da educação (MACAMO, 2017).

\subsection{Breve apanhado da Ginástica Rítimica no Brasil}

A Ginástica Rítmica foi trazida ao Brasil, através da professora Húngara Ilona Peuker, tendo como princípio a Cidade do Rio de Janeiro na década de 1950, quando ministrou vários cursos para profissionais da educação. Peuker com todos seus conhecimentos, formou a primeira equipe competitiva de GR chamado Grupo Unido de Ginastas (GUG), alcançando grande sucesso, frente a experiência e participação ativa nas práticas da ginástica internacional (TOLEDO, 1999).

Segundo Macamo (2017) o Brasil teve sua primeira participação em um campeonato mundial de GR com uma ginasta Daise Barros, em meados de 1971, em Copenhagen na Dinamarca, onde o Grupo Unido de Ginastas representou o Brasil em campeonatos internacionais e Gimnastradas, tendo conseguido o $13^{\circ}$ lugar no Campeonato Mundial de GR em 1973 na cidade de Roterdam, Holanda, realizando exercícios de Conjunto. As componentes daquela equipe posteriormente difundiram a GR por todo Brasil.

Assim, com a criação da Confederação Brasileira de Ginástica, no ano de 1978, esta modalidade começou a evoluir devido ao apoio recebido, resultando na classificação de ginastas para disputarem Jogos Olímpicos: a ginasta Rosane Favilla foi a primeira brasileira a participar dos Jogos Olímpicos, em 1984, Los Angeles, USA, com exercícios individuais. Em 1988, na Olimpíada se Seul, Coréia, a ginasta Marta Cristina Schonhorst esteve presente realizando exercícios individuais (RINALDI e SOUZA, 2003).

A GR teve grande apoio e incentivo de entidades governamentais ao esporte e o exaustivo trabalho de ginastas e técnicas, levaram a um grande crescimento da GR, possibilitando a equipe Brasileira alcançar a vitória em três Pan-americanos, nos exercícios de conjunto: Winnipeg, Canadá, em 1999, classificando o Brasil para a Olimpíada de Sydney, na Austrália; Santo Domingo, República Dominicana, em 2003, classificando o Brasil para a Olimpíada de Atenas na Grécia; Rio de Janeiro, Brasil, em 2007, classificando o Brasil para as Olimpíada de Pequim, na China. Nas duas Olimpíadas com a participação da equipe brasileira de Conjunto Sydney e Atenas - o Brasil foi finalista, obtendo o 
resultado de $8^{\circ}$ lugar (RINALDI e SOUZA, 2003).

Nos exercícios individuais destaca-se o resultado de $3^{\text {o }}$ lugar no aparelho Maças, obtido pela ginasta Taiane Montovanelli no Pan-americano de Santo Domingo e o resultado de $3^{\text {o }}$ lugar no aparelho Arco obtido pela ginasta Ana Paula Sheffer no Panamericano do Rio de Janeiro (REGO, 2009).

\subsection{Métodos de aprendizagem da Ginástica Rítmica na escola}

O método de ensino do professor necessita-se então ter mais ênfase na ação de dirigir e estimular o processo de aprendizagem dos discentes, utilizando-se de todos os mecanismos que indiquem os fundamentos e sistemas técnicos e táticos, compreendendose de maneira eficiente e cientifica como todos estes ensinamentos são estabelecidos para que então assim encontre um maior numero de iniciantes envolvidos nesta pratica corporal.

De acordo com OLIVEIRA (2003, p.43):

\section{A aprendizagem é consequência dos processos singulares e particulares,} dependendo característica de cada discente, de acordo com suas vivencias, variando com a capacidade, motivação e interesse de cada um. (OLIVEIRA ,2003, p.43).

Portanto faz-se de suma importância que o educador leve em consideração a potencialidade e o interesse de cada um dos seus, conscientizando, instigando e estimulando a criatividade, o lúdico e o agradável, no decorrer das atividades propostas e aplicados acerca da Gonástica Rítmica (LAFFRANCHI, 200I).

Os professores integrados ao espírito da nova educação, baseando-se em métodos que estimulem o amor pelo conhecimento por parte dos seus alunos, deve buscar/criar meios com base incondicional no exercício do desenvolvimento das faculdades humanas, mostrando então aos seus o belo, estimulando a imaginação e a sensibilidade, uma vez que estes atributos centrais que cada um traz consigo mesmo e que será suficientemente desenvolvido (GAIO, 2008).

A Ginástica Rítmica constitui-se assim, uma base incondicional na aplicação para o desenvolvimento de uma identidade continua de formação do aluno, porémm isto requer ao professor uma relativa sensibilidade e intuição,com a finalidade de criar conforme vibração especial que transmite-lhe cada ambiente, pois o educador tem este 
comprometimento de conscientizar os seus das atividades que serão exercidas por eles e a eles, explicando passo-a-passo e se preciso for, por várias vezes (LAFFRANCHI, 200I).

Tende-se aqui uma maior valorização da influência sobre a aplicação/compreensão dos conteúdos modernos relacionados para os aprendizes com relevância á compreensão do sentido/significado, vinculados á realidade social em que vivem. Garantir ao educando a compreensão social do conteúdo proposto em seus importantes quesitos, oferecendo subsídios atuais, abordando a dimensão do ensino dos fundamentos técnicos e táticos, adequando estes conteúdos á prática social nas diversas áreas da Ginástica Rítimica, legitimando-se assim, as possibilidades sócio-cognitivas dos discentes enquanto sujeitosativos (TAKADA e LOURENÇO, 2004).

\section{CONSIDERAÇÕES FINAIS}

A escola passa a ser um lugar de trabalho, de ensino e de aprender. Ł̀ na convivência diária que se instaura o ato de pensar, de agir e de coragem que se sustentam no diálogo, na discussão e no debate, onde desta maneira, o professor deve explicitar as tendências lúdicas e pedagógicas que existem no campo da Educação Física por meio da prática da Ginástica Rítmica escolar e assim sendo, buscar fazer um direcionamento através da introdução do ensino das técnicas e táticas do esporte, para a formação de valores globais e sociais na vida dos educandos, buscando perspectivas de aplicar as novas tendências ao ensino da modalidade esportiva coletiva que é o handebol, onde ele pode reencontrar o lúdico das práticas esportivas, nas aulas de Educação Física Escolar, percebendo o quanto ele é de suma importância para o desejo de preservar os valores humanos.

Assim, ao término desse estudo, pode-se concluir o quão faz-se preciso compreender que o ensino deve ser orientado na direção para a tomada de decisões e para o exercício da prática de uma responsabilidade social e política, for fornecendo significativas contribuições pedagógicas na implantação do pensamento crítico científico na área das atividades corporais de movimentos, caracterizando-se assim novas abordagens oriundas da literatura a respeito do ensino das técnicas, contrapondo ao tradicionalismo e então, propor aulas diversificadas e inovadoras acerca das modalidades da Ginástica na realidade escolar. 
A prática corporal é um elo que une os indivíduos, oferecendo uma possibilidade significativa a interação entre os seres, nos efeitos de sentido que concretizam o dizer e que também é por meio dele que se encontra a arte, ele é a porta de entrada e percepção para viver a magia do dar forma e existência ao que se sente e/ou mesmo os grupos que são e o próprio universo a ele dedicado.

É também por meio do ensino das práticas corporais, nas aulas de Educação Física Escolar, tendo como foco a Ginástica Rítmica, propicia uma imensa imprevisibilidade, aleatoriedade e variabilidade, distinguindo-se de outros esportes individuais com diversos ângulos de visão, que influenciam assim o desempenho de cada um dos seus, em uma competição, instigando-se assim as aplicações das maneiras de controle dos órgãos sensoriais, inferindo-se na motricidade da ação, dos rendimentos coordenativos exigidos assim nessas atividades de movimento.

\section{REFERÊNCIAS}

BREGOLATO, Roseli Aparecida. A cultura corporal da ginástica: Coleção Educação Física escolar: no principio da totalidade e na concepção histórico-críticosocial. São Paulo: Ícone, 2006.

DARIDO, S.C. A educação física na escola e o processo de formação dos não praticantes de atividade física. Revista Brasileira de Educação Física e Esportes, São Paulo, v.ı, n.I, p.6I-8o, 2005.

GAIO, Roberta. Ginástica Rítmica para tu, eles e nós. In: GAIO, Roberta. (Org) Ginástica Rítmica: Da Iniciação ao Alto Nível. Jundiaí: Fontoura, 2008.

LAFFRANCHI, Bárbara. Treinamento Aplicado á Ginástica Rítmica. Londrina: UNOPAR, 2001.

LIBÂNEO, José Carlos. Didática. São Paulo: Cortez. (Coleção Magistério 2º Grau, Série Formação do Professor). 1994. 
MACAMO, Arestides Joaquim. A Ginástica Em Questão: Fatores Que Corroboram Para Sua Extinção Da Prática Do Profissional De Educação Física Florianópolis, 2017.

Disponível em:

https://repositorio.ufsc.br/bitstream/handle/123456789/181914/TCC\%2oArestides\%2oMac amo.pdf? sequence $=\mathrm{I} \&$ is Allowed $=\mathrm{y}$. Acesso em: 30 de Out. 2021.

MOYLES, Janet R. Só Brincar? O papel do brincar na educação infantil. Porto Alegre: Artmed Editora. 2002.

MARCASSA, Luciana. A Ginástica escolar no currículo da FEF/UFG: uma trajetória possível. VII Semana Científica da Faculdade de Educação Física da UFG, Anais ... Jataí, 2002.

OLIVEIRA, S. C. V et al., Docência universitária e currículo: analisando a formação profissional do professor de Educação Física. Coleção Pesquisa em Educação Física. v.II, n.I, p. I49-158, 2012.

TAKADA, S. R.; LOURENÇO, M. R. A. Menarca tardia e osteopenia em atletas de Ginástica Rítmica: uma revisão de literatura. UNOPAR Cient., Ciênc. Biol. Saúde, Londrina, v. 6, n. I, p. 41-47, out. 2004.

TOLEDO, E. de. Proposta de conteúdos para a ginástica escolar: um paralelo com a Teoria de Coll. Dissertação (Mestrado em Educação Física) - Universidade Estadual de Campinas, Campinas, I999.

REGO, Mayara N.; LIMA, Priscila F. A função sócio-afetiva da Ginástica Rítmica: Diferentes percepções num Projeto Sócio - Esportivo. Trabalho de Conclusão de Curso (Bacharel em Educação Física) - UNOPAR, 2009.

RINALDI, I.P.B.; SOUZA, E.P.M. A ginástica no percurso escolar dos ingressantes dos cursos de licenciatura em educação física da Universidade Estadual de Maringá e da 
Universidade Estadual de Campinas. Rev. Bras. Cienc. Esporte, Campinas, v.24, p. 159-173, 2003.

RODRIGUES, Maria B. Educação escolar como instrumento de mediação na relação Estado/Povo: a Reforma Mato-grossense em 1910 - fase de implantação. Dissertação de Mestrado. PUC/SP.1988. 